\title{
Tumor Mutational Patterns and Infiltrating Lymphocyte Density in Young and Elderly Patients With Breast Cancer
}

\author{
ADAMANTIA NIKOLAIDI ${ }^{*}$, VASSILIKI KOTOULA ${ }^{2,3 *}$, GEORGIA-ANGELIKI KOLIOU ${ }^{4}$, \\ ELENI GIANNOULATOU ${ }^{5,6}$, KYRIAKI PAPADOPOULOU ${ }^{3}$, FLORA ZAGOURI ${ }^{7}$, GEORGE PENTHEROUDAKIS GL, $^{8,9}$ \\ HELEN GOGAS ${ }^{10}$, MATTHEOS BOBOS ${ }^{3}$, KYRIAKOS CHATZOPOULOS ${ }^{3}$, GEORGIOS OIKONOMOPOULOS ${ }^{11}$, \\ DIMITRIOS PECTASIDES ${ }^{12}$, EMMANOUIL SALOUSTROS ${ }^{13}$, NIKI ARNOGIANNAKI ${ }^{14}$, \\ IRENE NICOLAOU $^{15}$, PAVLOS PAPAKOSTAS ${ }^{16}$, ILIADA BOMPOLAKI ${ }^{17}$, \\ GERASIMOS ARAVANTINOS $^{18}$, ILIAS ATHANASIADIS ${ }^{1}$ and GEORGE FOUNTZILAS 3 ,19,20 \\ ${ }^{1}$ Oncology Department Mitera Hospital, Athens, Greece; \\ ${ }^{2}$ Department of Pathology, School of Health Sciences, Faculty of Medicine, \\ Aristotle University of Thessaloniki, Thessaloniki, Greece; \\ ${ }^{3}$ Laboratory of Molecular Oncology, Hellenic Foundation for Cancer \\ Research/Aristotle University of Thessaloniki, Thessaloniki, Greece; \\ ${ }^{4}$ Section of Biostatistics, Hellenic Cooperative Oncology Group, Data Office, Athens, Greece; \\ ${ }^{5}$ Bioinformatics and Systems Medicine Laboratory, Victor Chang Cardiac \\ Research Institute, Darlinghurst, NSW, Australia; \\ ${ }^{6}$ The University of New South Wales, Kensington, NSW, Australia; \\ ${ }^{7}$ Department of Clinical Therapeutics, Alexandra Hospital, \\ National and Kapodistrian University of Athens School of Medicine, Athens, Greece; \\ ${ }^{8}$ Department of Medical Oncology, Medical School, University of Ioannina, Ioannina, Greece; \\ ${ }^{9}$ Society for Study of Clonal Heterogeneity of Neoplasia (EMEKEN), Ioannina, Greece; \\ ${ }^{10}$ First Department of Medicine, Laiko General Hospital, National and \\ Kapodistrian University of Athens School of Medicine, Athens, Greece; \\ ${ }^{11}$ Second Department of Medical Oncology, Metropolitan Hospital, Piraeus, Greece; \\ ${ }^{12}$ Oncology Section, Second Department of Internal Medicine, Hippokration Hospital, Athens, Greece; \\ ${ }^{13}$ Department of Oncology, University Hospital of Larissa, Larissa, Greece; \\ ${ }^{14}$ Department of Surgical Pathology, Saint Savvas Anticancer Hospital, Athens, Greece; \\ ${ }^{15}$ Department of Histopathology, Agii Anagriri Hospital, Athens, Greece; \\ ${ }^{16}$ Oncology Unit, Hippokration Hospital, Athens, Greece; \\ ${ }^{17}$ Oncology Department, General Hospital of Chania, Chania, Greece; \\ ${ }^{18}$ Second Department of Medical Oncology, Agii Anargiri Cancer Hospital, Athens, Greece; \\ ${ }^{19}$ Aristotle University of Thessaloniki, Thessaloniki, Greece; \\ ${ }^{20}$ German Oncology Center, Limassol, Cyprus
}

This article is freely accessible online.

*The first two Authors (AN and VK) have equally contributed to this work.

Correspondence to: Adamantia Nikolaidi, Oncology Department, Mitera Hospital, Athens, Greece. Tel: +30 2106869853, e-mail: mantonikolaidi@gmail.com; hecogoff@otenet.gr

Key Words: Age, genotype, stromal TIL density, co-mutation, NGS.

\begin{abstract}
Background/Aim: Age may pertain to different tumor genotype characteristics which may interfere with treatment efficacy and prognosis. We investigated the distribution and prognostic effect of mutations and tumor infiltrating lymphocyte (stromal TIL density) in young ( $\leq 35$ years) and elderly (>65 years) early breast cancer patients. Materials and Methods: Paraffin tumor genotypes of all clinical subtypes from 345 patients were examined. Results: A total of 638 mutations were detected in 221 patients (64.1\%). Compared to young, elderly patients presented with lower TIL density $(p<0.001)$ but more
\end{abstract}


TILs in TP53 mutated tumors ( $p=0.042)$. Mutation in one, rather than in 2 or more genes, conferred better outcome (DFS: $H R=0.51, p=0.016 ;$ OS: HR=0.47, $p=0.015$ ) but the effect was age-independent. Conclusion: There are fewer TILs and different mutations patterns in tumors from elderly patients compared to young. Age and TIL-independent gene agnostic co-mutations affect patient outcome.

Breast cancer (BC) is known to be a heterogeneous disease and besides the classic biological predictors, age at diagnosis has been proven as an independent prognostic factor in several studies $(1,2)$. Age is confirmed as an independent prognostic variable for locoregional-free interval, distant metastasis-free interval and breast cancer specific survival (3-6). Among women diagnosed with breast cancer during 1996-2000, $44.2 \%$ were aged 65 or more years and only $2 \%$ were $<35$ years (7), although the latter incidence may be higher in specific ethnic groups (8). Compared to elderly, postmenopausal patients, young breast cancer patients more often have a family history of malignancy, deleterious germline mutations in BRCA1/2 and other highly penetrant cancer predisposing genes, such as TP53, and they also present with more aggressive disease: poorly differentiated, HER2-positive or triple negative (TNBC) tumors (9). Breast cancer in the young has been associated with increased likeliness for metastases $(10,11)$, with poor overall prognosis $(10,12)$, even for stage I-II disease $(1,13)$, while the underlying biology of tumors in this age group has seldom been described in a context other than inherited breast cancer predisposition (14).

TP53 and PIK3CA mutations are the most frequent genetic alterations in breast cancer, with a similar prevalence for both genes, observed in 26-36\% of breast carcinomas based on data from COSMIC and cBioPortal. TP53 mutant genotypes are unfavorable prognosticators in Luminal $\mathrm{A} / \mathrm{B}$ and $\mathrm{TNBC}$ patients (15). TP53 and PIK3CA mutations appear to have diverse effects on the outcome of early BC patients, according to whether these genes are co-mutated or not, and for TP53 according to stromal TIL density and ER/PgR-status $(16,17)$.

In this study, we assumed that differences in the prognosis of young and elderly patients with BC may be associated with different genotype characteristics and with the efficiency of immune response in the two age groups. We investigated the distribution and prognostic effect of tumor mutations and TIL density in young, $\leq 35$ years old and elderly $>65$ years old early breast cancer patients, treated with adjuvant chemotherapy in the context of clinical trials.

\section{Materials and Methods}

Paraffin tumors (FFPE) from 345 out of 1,502 early breast cancer patients with next generation sequencing (NGS) informative data were examined. All patients had been treated with adjuvant chemotherapy in the setting of four prospective trials conducted by the Hellenic Cooperative Oncology group (HE10/97; HE10/00;
HE10/05; HE10/08) as previously described (18). In the HE10/05 and HE10/08 studies, patients had received trastuzumab treatment for HER2-positive disease sequentially for one year upon completion of chemotherapy (post-trastuzumab era), while they did not in earlier studies (HE10/97 and HE10/00, pre-trastuzumab era). All patients had provided written consent for the use of their biologic material for research purposes and the study was approved by the Bioethics Committee of the Aristotle University of Thessaloniki School of Health Sciences, Faculty of Medicine (\#77/10June2014) and by the Institutional Review Board of the Papageorgiou Hospital of Thessaloniki (\#725/10May2013). Patients had received adjuvant hormone therapy and trastuzumab based on ER/PgR/HER2 immunohistochemistry (IHC) subtyping at local pathology laboratories following initial diagnosis. Subsequently, FFPE tumors were centrally processed at the Laboratory of Molecular Oncology (Hellenic Foundation for Cancer Research/Aristotle University of Thessaloniki) for histology review and subtyping with ER/PgR/HER2/Ki67 IHC and fluorescent in situ hybridization for HER2 (15), for stromal tumor infiltrating lymphocyte (TIL) density, as previously described (18), and for DNA extraction and next-generation sequencing (NGS) genotyping.

NGS genotyping. FFPE tumor genotypes were obtained by semiconductor sequencing with a panel covering 34845 nucleotides in coding regions of 59 genes (19). The examined 345 samples contained $>50 \%$ cancer cell DNA in $>90 \%$ of the cases, exhibited on average 18 variants ( $\min 5-\max 182$ ), their average mean depth was 1605.7 ( $\min 106.3-\max 22852)$, and their average uniformity was $75.3 \%$ ( $\min 50.3 \%-\max 92.1 \%$ ). Variants were accepted if allele frequency $\geq 5 \%$, quality of position reads $p<0.0001$, lack of GC-stretches, position coverage $>100$ and variant coverage $>40$. Amino acid and splice-site changing variants with population minor allele frequencies $<0.1 \%$ (dbSNP, 5000Exomes) were considered as mutations. Pathogenic mutations were not distinguished, since the majority can still only be presumed, and this with an accuracy of $\sim 70 \%$ (20), while their coexistence in tumors may not always result in the expected pathogenic effect (21).

Statistical analysis. Frequencies with the corresponding percentages were used to summarize categorical data, while medians and range were used to describe continuous variables. Associations between selected genes' mutational status and several clinicopathological parameters were assessed with the chi-square or Fisher's exact test (where appropriate). The non-parametric Wilcoxon rank-sum test was used to detect differences in continuous variables between young and elderly patients and in the groups defined by the selected genes' mutational status.

Disease-free survival (DFS) was estimated from the time of breast cancer diagnosis to the date of first documented progression, death (from any cause) or last contact (whichever occurred first). Overall survival (OS) was also estimated from the date of diagnosis to the date of patient's death. Alive patients were censored at the date of last contact. Time-to-event distributions were estimated with the Kaplan-Meier product limit method and compared among groups with the two-sided log-rank test. Time-dependent covariates were used to evaluate proportionality for all parameters.

The effect of mutations in several genes and other clinicopathological parameters of interest on patients' DFS and OS were examined with hazard ratios (HR) estimated with univariate and multivariate Cox proportional regression models in the entire cohort $(\mathrm{N}=345)$ and separately in young $(\mathrm{N}=88)$ and old patients $(\mathrm{N}=257)$. 
In multivariate analysis, in the entire cohort, a backwards selection procedure with a removal criterion of $p>0.10$ was used with the following parameters in the initial step of the model: number of positive nodes $(0-3, \geq 4)$, PIK3CA/TP53 mutational status (mutations in both genes, none, PIK3CA mutations only, TP53 mutations only, no mutations), number of mutated genes per tumor (none mutated, 1 mutated, $\geq 2$ mutated), TILs (10\% increments) and age group (young, elderly) with respect to DFS and number of positive nodes $(0-3, \geq 4)$, PIK3CA/TP53 mutational status (mutations in both genes, none, PIK3CA mutations only, TP53 mutations only, no mutations), number of mutated genes per tumor (none mutated, 1 mutated, $\geq 2$ mutated) and age group (young, elderly) with respect to OS. Except for the two age groups that were study objectives included in both models, despite non-significant differences in outcome, the parameters selected for inclusion in the first step of each model were variables that showed (marginal) significance $(p<0.050)$ in the univariate analyses.

All tests were two-sided and the level of significance was set at $5 \%$. Adjustment for multiple comparisons was not applied given that this study was exploratory and mainly hypothesis generating with predefined parameters. The SAS version 9.3 (SAS Institute) was used for data manipulation and statistical analyses. The $\mathrm{R}$ studio version 3.5.0 was used to produce maps with the mutation pattern of genes and violin plots.

\section{Results}

The 345 patients included in this study were categorized in two groups based on their age at diagnosis (88 young vs. 257 elderly). In total, 109 women were treated in the pretrastuzumab era (32 young and 77 elderly), while the rest 236 patients $(68.4 \%)$ received adjuvant chemotherapy in the posttrastuzumab era (56 young and 180 elderly). Basic patient and tumor characteristics for the entire cohort and by age group are presented in Table I. Elderly women presented with lower TIL density and Ki67 labeling (both Wilcoxon rank sum $p<0.001$, Figure 1A) and were more frequently of the invasive ductal histological type (chi-square $p=0.032$ ), while no further differences were detected in the examined clinicopathological parameters by age group. Of the 20 young patients with HER2positive tumors, only 7 were treated in the pre-trastuzumab era, whereas 19 of the 53 elderly patients with HER2-positive tumors received adjuvant treatment in the pre-trastuzumab era.

In total, 638 mutations (median 1 per tumor; range=0-58) were observed in the tumors of 221 patients $(64.1 \%)$ and concerned 48 genes out of 59 targeted with the panel. Fiftyfour of the 88 tumors from young patients $(61.4 \%)$ carried 120 mutations in 30 genes; respectively, 167 of the 257 tumors from elderly patients $(65.0 \%)$ carried 518 mutations in 47 genes. Neither the number of mutations nor the number of mutated genes per tumor differed between young and older women (Table I). TP53 and PIK3CA were the most commonly mutated genes in the entire cohort of patients in both age groups, as depicted in Figure 1B. In total, 27\% of the study population carried mutations in PIK3CA and $25.2 \%$ in TP53. In elderly patients, $29.2 \%$ and $22.6 \%$ of the tumors had mutations in PIK3CA and TP53, respectively. In comparison, the respective prevalence was inverted in young patients, with $20.5 \%$ and $33.0 \%$ of the tumors carrying mutations in PIK3CA and TP53, but this difference did not reach statistical significance. The mutant allele fraction and the number of tumors with hotspot mutations in these genes did not differ in the two age groups.

GATA3 mutations were observed in $10.2 \%$ and $5.4 \%$ in young and elderly patients, respectively, again a difference that did not reach statistical significance $(p=0.12)$. Interestingly though, in 7 out of 9 tumors from young patients with GATA3 mutations, these variants were missense or frameshifts at p.Pro409, pathogenic according to COSMIC, and were present at a high fraction $(>25 \%)$ in the examined samples. Variants at a high allelic fraction at the same codon and overall pathogenic/deleterious variants in the same coding region were observed in only 3 out 14 GATA3 mutated tumors from older patients. All 11 EGFR mutated tumors (3.2\% of all tumors) were detected in elderly patients (Fisher's $p=0.049$ ) but none of these $E G F R$ mutations was actionable. In addition, 24 of the 26 tumors $(92.3 \%)$ with mutations in MAP3K1 and 17 of the $18(94.4 \%)$ with mutations in PTEN were from patients of older age ( $p=0.030$ and $p=0.046$, respectively). The single young patient with a PTEN mutated tumor carried one frameshift (p.Ile253Asn/c.756_757insA) variant of unknown significance (VUS) at an allele frequency of $46 \%$, and an additional stop-gain variant (p.Arg233*/c.697C > T) at an allele frequency of $56 \%$. MAP3K1 variants were of low allele frequency in tumors from young patients $(<10 \%)$ and occurred at high frequency in tumors from 3 older patients only.

As can be inferred from Figure $1 \mathrm{~B},>50 \%$ of the tumors with PIK3CA or TP53 mutations also carried mutations in one or more additional genes; however, these two genes were not preferentially co-mutated. Seventy-one patients $(20.6 \%)$ had only PIK3CA mutations (11 young, 12.5\%; 60 elderly, $23.3 \%), 65$ patients $(18.8 \%)$ had only TP53 mutations (22 young, $25.0 \%$; 43 elderly, 16.7\%), while 22 patients carried mutations in both genes (7 young, $8.0 \%$; 15 elderly, 5.8\%) and $18.3 \%$ of the study population had mutations in genes other than TP53 and PIK3CA.

The associations of selected clinicopathological parameters with the mutational status of TP53 and PIK3CA in the entire cohort and in the subgroups of young and elderly patients are presented in Table II. In the entire cohort, tumors with PIK3CA mutations were less frequently HER2-positive (chisquare $p<0.001)$, while tumors with TP53 mutations presented with higher TIL density and Ki67 levels (Wilcoxon rank-sum $p=0.004$ and $p<0.001$, respectively; Figure 2A), and were less frequently of lower grade (chi-square $p<0.001$ ), HER2-negative $(p=0.005)$ and ER/PgR positive $(p=0.001)$, compared to those without mutations in these genes. In elderly patients, TP53 mutated tumors had higher TIL density and Ki67 levels (Wilcoxon rank-sum $p=0.042$ and $p<0.001$, 
Table I. Selected patient and tumor characteristics.

\begin{tabular}{|c|c|c|c|c|}
\hline & $\begin{array}{c}\text { Total } \\
(\mathrm{N}=345)\end{array}$ & $\begin{array}{l}\text { Young } \\
(\mathrm{N}=88)\end{array}$ & $\begin{array}{c}\text { Elderly } \\
(\mathrm{N}=257)\end{array}$ & $p$-Value \\
\hline TILs & $5.0(0.00,95.0)$ & $10.0(0.00,85.0)$ & $5.0(0.00,95.0)$ & $<0.001^{\mathrm{a}}$ \\
\hline Ki67 & $25.0(0.00,98.0)$ & $35.0(0.00,97.0)$ & $20.0(0.00,98.0)$ & $<0.001^{a}$ \\
\hline $\mathrm{N}$ of mutations per tumor & $1.00(0.00,58.0)$ & $1.00(0.00,13.0)$ & $1.00(0.00,58.0)$ & $0.42^{\mathrm{a}}$ \\
\hline $\mathrm{N}$ of mutated genes per tumor & $1.00(0.00,23.0)$ & $1.00(0.00,10.0)$ & $1.00(0.00,23.0)$ & $0.35^{\mathrm{a}}$ \\
\hline $\mathrm{N}$ of positive nodes & $2.0(0.00,47.0)$ & $2.0(0.00,31.0)$ & $3.0(0.00,47.0)$ & $0.14^{\mathrm{a}}$ \\
\hline \multirow[t]{2}{*}{ Tumor size } & $2.5(0.00,10.0)$ & $3.0(0.20,8.0)$ & $2.5(0.00,10.0)$ & $0.099^{\mathrm{a}}$ \\
\hline & $\mathrm{N}(\%)$ & $\mathrm{N}(\%)$ & $\mathrm{N}(\%)$ & \\
\hline $\mathrm{N}$ of mutations per tumor & & & & $0.72^{\mathrm{b}}$ \\
\hline 1 mutation & $128(37.1)$ & $33(37.5)$ & $95(37.0)$ & \\
\hline$\geq 2$ mutations & $93(27.0)$ & $21(23.9)$ & $72(28.0)$ & \\
\hline no mutation & $124(35.9)$ & $34(38.6)$ & $90(35.0)$ & \\
\hline $\mathrm{N}$ of mutated genes per tumor & & & & $0.53^{b}$ \\
\hline 1 mutation & $135(39.1)$ & $36(40.9)$ & $99(38.5)$ & \\
\hline$\geq 2$ mutations & $86(24.9)$ & $18(20.5)$ & $68(26.5)$ & \\
\hline no mutation & $124(35.9)$ & $34(38.6)$ & $90(35.0)$ & \\
\hline $\mathrm{N}$ of positive nodes & & & & $0.62^{\mathrm{b}}$ \\
\hline $0-3$ & $200(58.0)$ & $53(60.2)$ & $147(57.2)$ & \\
\hline$\geq 4$ & $145(42.0)$ & $35(39.8)$ & $110(42.8)$ & \\
\hline Tumor size & & & & $0.67^{b}$ \\
\hline$\leq 2$ & $128(37.1)$ & $31(35.2)$ & $97(37.7)$ & \\
\hline$>2$ & $217(62.9)$ & $57(64.8)$ & $160(62.3)$ & \\
\hline Histology Grade* & & & & $0.096^{\mathrm{b}}$ \\
\hline I & $12(3.5)$ & $2(2.3)$ & $10(3.9)$ & \\
\hline II & $160(46.6)$ & 33 (37.9) & $127(49.6)$ & \\
\hline III & $171(49.9)$ & $52(59.8)$ & $119(46.5)$ & \\
\hline Histological type & & & & $0.032^{\mathrm{b}}$ \\
\hline Invasive ductal & $280(81.2)$ & $70(79.5)$ & $210(81.7)$ & \\
\hline Invasive lobular & $27(7.8)$ & $3(3.4)$ & $24(9.3)$ & \\
\hline Mixed & $12(3.5)$ & $3(3.4)$ & $9(3.5)$ & \\
\hline Other & $26(7.5)$ & $12(13.6)$ & $14(5.4)$ & \\
\hline HER2 status* & & & & $0.72^{b}$ \\
\hline Negative & $257(77.9)$ & $65(76.5)$ & $192(78.4)$ & \\
\hline Positive & $73(22.1)$ & $20(23.5)$ & $53(21.6)$ & \\
\hline ER/PgR status* & & & & $0.92^{\mathrm{b}}$ \\
\hline Negative & $59(18.2)$ & 15 (17.9) & $44(18.3)$ & \\
\hline Positive & $265(81.8)$ & $69(82.1)$ & $196(81.7)$ & \\
\hline Subtypes* & & & & $0.059^{b}$ \\
\hline HER2-Enriched & $18(5.6)$ & $4(4.8)$ & $14(5.8)$ & \\
\hline Luminal A & $101(31.2)$ & $16(19.0)$ & $85(35.4)$ & \\
\hline Luminal B & $112(34.6)$ & $37(44.0)$ & $75(31.3)$ & \\
\hline Luminal HER2 & $52(16.0)$ & $16(19.0)$ & $36(15.0)$ & \\
\hline TNBC & $41(12.7)$ & $11(13.1)$ & $30(12.5)$ & \\
\hline
\end{tabular}

*Data not available for all subjects. Missing values: Histology Grade=2, HER2 status=15, ER/PgR status=21, Subtypes=21. Values presented as Median (min, max) or N (column \%). p-Values: aWilcoxon-rank sum test, bPearson's chi-square/Fisher's exact test. Bold values show significance.

respectively), while $P I K 3 C A$ or $T P 53$ mutated tumors were less frequently HER2-negative (chi-square $p=0.002$ and $p=0.004$, respectively). In young patients, tumors with $T P 53$ mutations were less frequently of lower-grade $(p=0.030)$. Neither TIL density nor any other clinicopathological parameter was associated with the number of mutations per tumor or the number of mutated genes per tumor in the entire cohort or in the subgroups defined by age.
At a median follow-up of 7.0 years $(95 \% \mathrm{CI}=6.8-7.2)$, a total of 88 events of progression or death (DFS events) had occurred (25 in young patients, $28.4 \%$ and 63 in elderly patients, 24.5\%), while 69 patients had died (18 young patients, $20.5 \%$ and 51 elderly patients, $19.8 \%$ ). In the entire cohort and in the subgroup of elderly women, the median DFS and OS was 14.5 years, while the median DFS and OS had not been reached yet among young women. 

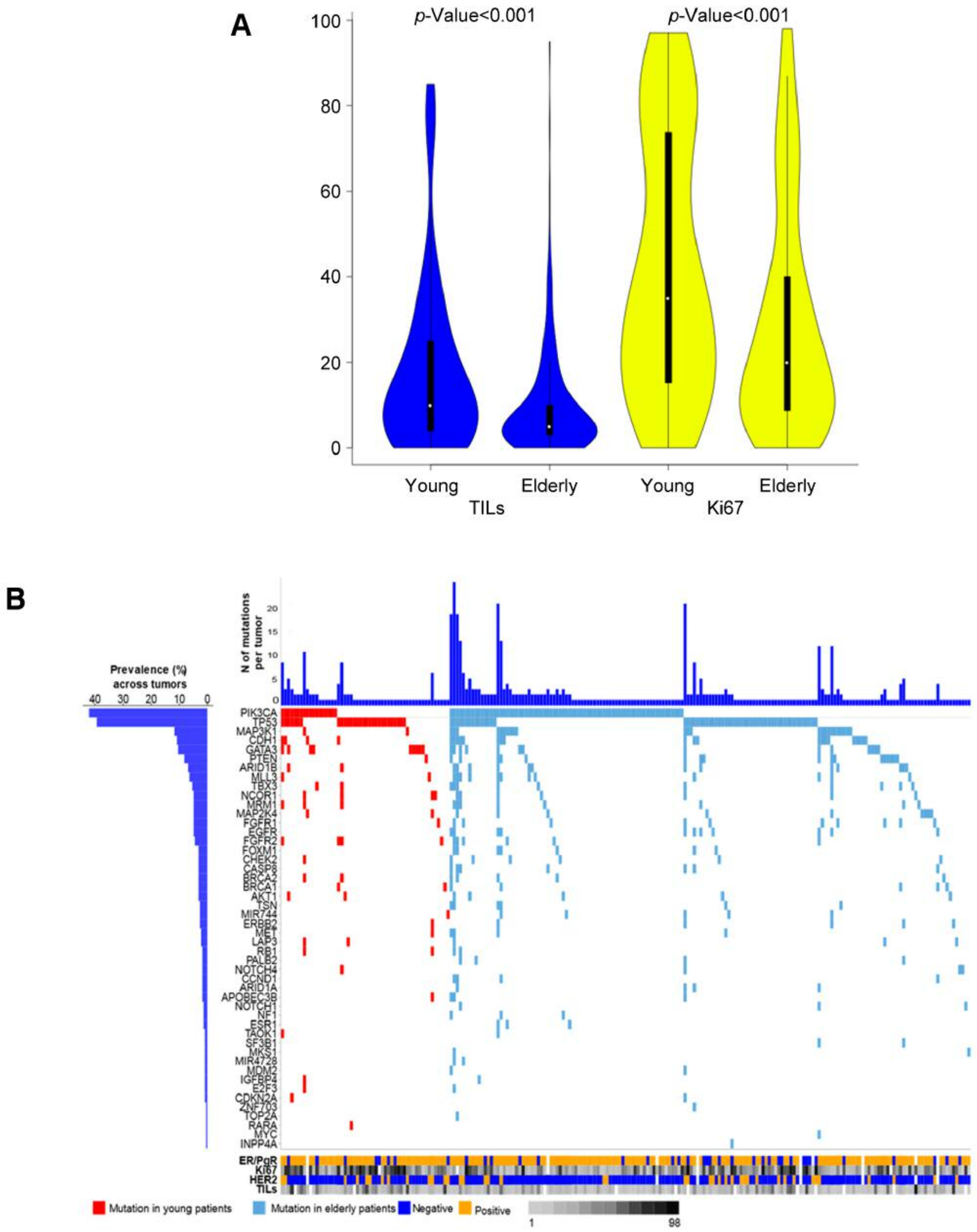

Figure 1. TILs and mutations in tumors from young and elderly patients with early breast cancer. (A) Violin plots of TIL density and Ki67 by age group in the entire cohort of patients, (B) Map showing the distribution of mutations per tumor by age group. 


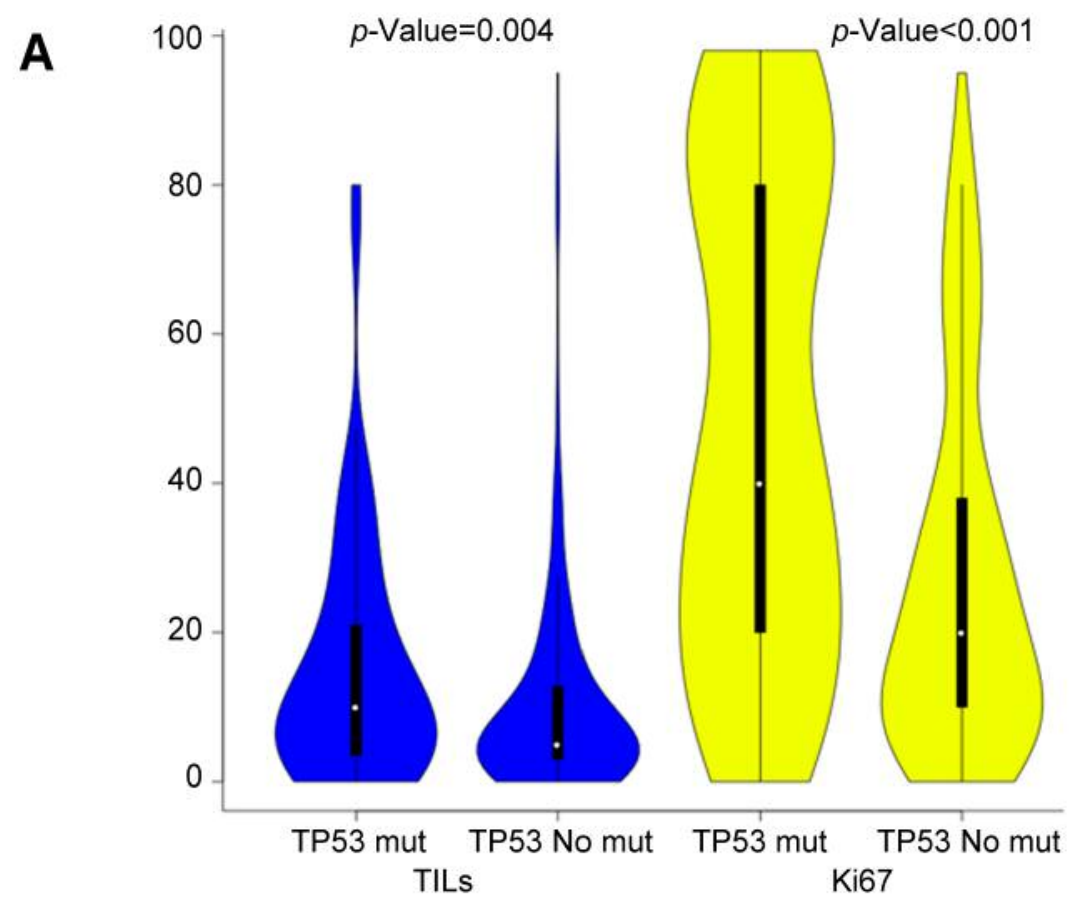

B
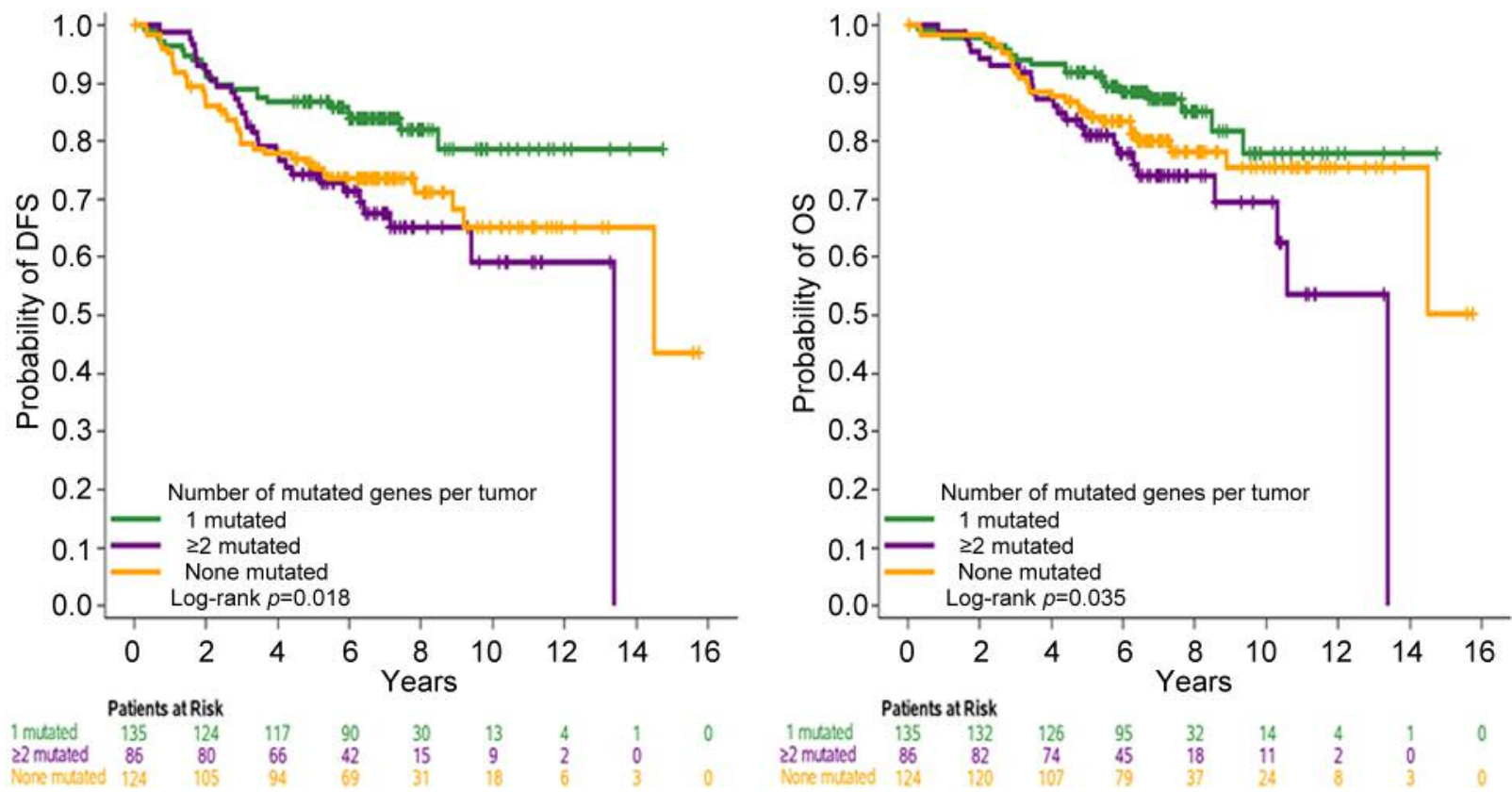

Figure 2. Genotype features associated with clinicopathological characteristics and patient outcome. (A) Violin plots of TIL density and Ki67 by TP53 mutational status, (B) Kaplan-Meier curves based on the number of mutated genes per tumor with respect to DFS and OS in the entire study cohort.

In the total cohort of patients $(\mathrm{N}=345)$, age was not associated with either DFS or OS (Wald's $p=0.60$ and $p=0.70$, respectively). Patients with mutations only in PIK3CA were at lower risk of progression and death compared to those carrying mutations in both PIK3CA and TP53 genes (HR=0.33, $p=0.013$ and $\mathrm{HR}=0.37$, 95\% $p=0.046$, respectively, Table III). Additionally, patients carrying only one mutation as well as those with mutations in only one gene had longer DFS and OS compared to those with two or more mutations or mutated genes. Increased TILs conferred marginally significantly lower 


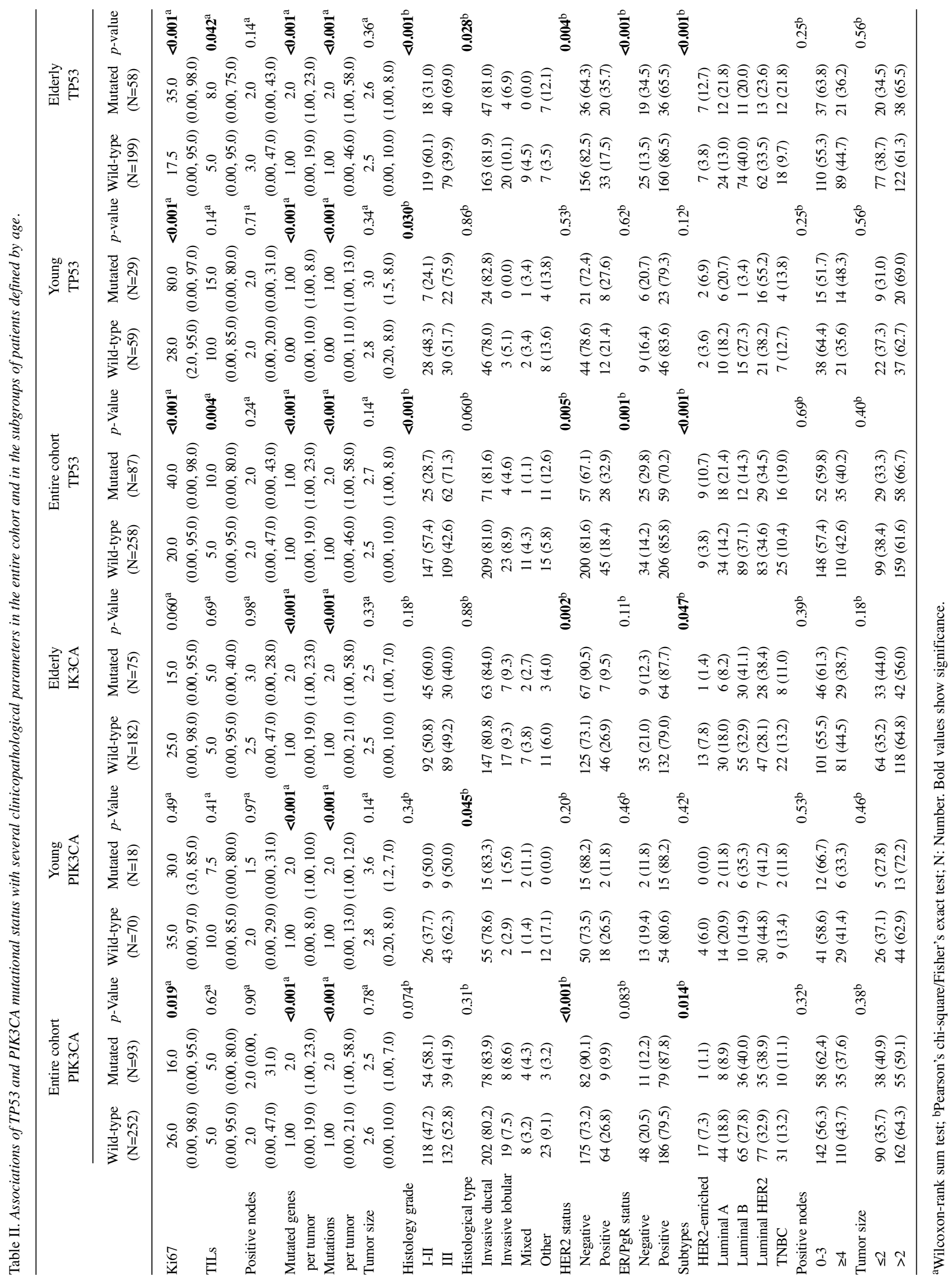


Table III. Hazard ratios and 95\% CIs estimated by univariate Cox regression with respect to disease-free survival (DFS) and overall survival (OS) in the total cohort of patients $(N=345)$.

\begin{tabular}{|c|c|c|c|c|c|c|}
\hline & Event/Total & Hazard ratio $(95 \% \mathrm{CI})$ & $p$-Value & Event/Total & Hazard ratio $(95 \% \mathrm{CI})$ & $p$-Value \\
\hline & \multicolumn{3}{|c|}{ DFS } & \multicolumn{3}{|c|}{ OS } \\
\hline \multicolumn{7}{|l|}{ Age group } \\
\hline Young $(\leq 35)$ & $25 / 88$ & $1.13(0.71-1.80)$ & 0.60 & $18 / 88$ & $0.90(0.52-1.54)$ & 0.70 \\
\hline Elderly $(>65)$ & $63 / 257$ & Reference & -- & $51 / 257$ & Reference & -- \\
\hline \multicolumn{7}{|l|}{ Positive nodes } \\
\hline $0-3$ & $35 / 200$ & Reference & -- & $21 / 200$ & Reference & -- \\
\hline$\geq 4$ & $53 / 145$ & $2.22(1.44-3.40)$ & $<0.001$ & $48 / 145$ & $3.17(1.89-5.30)$ & $<0.001$ \\
\hline \multicolumn{7}{|l|}{$P I K 3 C A$} \\
\hline Mutated & $20 / 93$ & $0.78(0.47-1.29)$ & 0.34 & $16 / 93$ & $0.87(0.50-1.53)$ & 0.63 \\
\hline Wild-type & $68 / 252$ & Reference & -- & $53 / 252$ & Reference & -- \\
\hline \multicolumn{7}{|l|}{ TP53 } \\
\hline Mutated & $24 / 87$ & $1.07(0.67-1.72)$ & 0.76 & $19 / 87$ & $1.09(0.64-1.85)$ & 0.75 \\
\hline Wild-type & $64 / 258$ & Reference & -- & $50 / 258$ & Reference & -- \\
\hline \multicolumn{7}{|l|}{ PIK3CA/TP53 } \\
\hline No mutation & $36 / 124$ & $0.65(0.31-1.35)$ & 0.25 & $26 / 124$ & $0.57(0.24-1.31)$ & 0.18 \\
\hline PIK3CA mutation only & $11 / 71$ & $0.33(0.14-0.79)$ & 0.013 & 9/71 & $0.37(0.14-0.98)$ & 0.046 \\
\hline TP53 mutation only & $15 / 65$ & $0.48(0.21-1.09)$ & 0.080 & $12 / 65$ & $0.48(0.19-1.23)$ & 0.13 \\
\hline Both & $9 / 22$ & Reference & -- & $7 / 22$ & Reference & -- \\
\hline None mutated ${ }^{1}$ & $17 / 63$ & $0.63(0.28-1.42)$ & 0.27 & $15 / 63$ & $0.72(0.30-1.78)$ & 0.48 \\
\hline TILs* & & $0.82(0.67-1.00)$ & 0.048 & & $0.83(0.66-1.03)$ & 0.096 \\
\hline Ki67^ & & $1.00(0.99-1.01)$ & 0.99 & & $1.00(0.99-1.01)$ & 0.51 \\
\hline Mutations per tumor ${ }^{\wedge}$ & & $0.99(0.95-1.00)$ & 0.72 & & $0.98(0.92-1.05)$ & 0.57 \\
\hline Mutated genes per tumor^ & & $1.00(0.92-1.08)$ & 0.91 & & $0.99(0.91-1.09)$ & 0.90 \\
\hline \multicolumn{7}{|l|}{ Mutations per tumor } \\
\hline 1 mutation & $22 / 128$ & $0.49(0.29-0.86)$ & 0.012 & $18 / 128$ & $0.47(0.26-0.87)$ & 0.016 \\
\hline$\geq 2$ mutations & $30 / 93$ & Reference & -- & $25 / 93$ & Reference & -- \\
\hline No mutation & $36 / 124$ & $0.88(0.54-1.43)$ & 0.61 & $26 / 124$ & $0.69(0.40-1.21)$ & 0.19 \\
\hline \multicolumn{7}{|l|}{ Mutated genes per tumor } \\
\hline 1 mutated & $23 / 135$ & $0.47(0.27-0.82)$ & 0.008 & $19 / 135$ & $0.46(0.25-0.84)$ & 0.011 \\
\hline$\geq 2$ mutated & $29 / 86$ & Reference & -- & $24 / 86$ & Reference & -- \\
\hline None mutated & $36 / 124$ & $0.85(0.52-1.39)$ & 0.51 & $26 / 124$ & $0.67(0.38-1.17)$ & 0.16 \\
\hline
\end{tabular}

${ }^{1}$ None of the PIK3CA and TP53 were mutated; ^ continuous variable; *10\% increments. Bold values show significance.

risk of progression $(\mathrm{HR}=0.82,95 \% \mathrm{CI}=0.67-1.00$ for each $10 \%$ TIL increment, $p=0.048$ ) (Table III). Likewise, elderly patients with only one mutation or with mutations in only one gene were at lower risk of progression and death compared to those with multiple mutations or multiple mutated genes (Table IV). Of note, tumors with multiple mutated genes and tumors without detected mutations with the applied panel were associated with similar outcomes (Figure 2B). No significant associations were detected between any of the examined parameters and DFS or OS among young women (Table V). Regarding the effect of clinicopathological parameters on patient outcome, only the number of positive nodes was found to be of prognostic significance for both DFS and OS. Women with four or more positive nodes were at higher risk of progression and death in the entire cohort of patients as well as in the subgroups of young (DFS: $\mathrm{HR}=2.79,95 \% \mathrm{CI}=1.23-6.33, p=0.014$ and $\mathrm{OS}$ : $\mathrm{HR}=2.52,95 \% \mathrm{CI}=0.94-6.78, p=0.066$, respectively) and elderly patients (DFS: $\mathrm{HR}=2.02,95 \% \mathrm{CI}=1.22-3.35, p=0.006$ and $\mathrm{OS}$ : $\mathrm{HR}=3.39,95 \% \mathrm{CI}=1.85-6.21, p<0.001$, respectively).

Upon multivariate analysis, in the entire cohort, the presence of mutations only in one gene retained its favorable prognostic significance for both DFS and OS $(\mathrm{HR}=0.51$, $95 \% \mathrm{CI}=0.29-0.88, p=0.016$ and $\mathrm{HR}=0.47,95 \% \mathrm{CI}=0.26-0.86$, $p=0.015$, respectively) but was independent of age (Table VI).

\section{Discussion}

Analyses comparing breast cancer in young $v s$. old women have as yet focused on the worse prognosis usually reported for younger women and on the increased frequency of inherited disease in this group of patients. Here, we investigated the impact of age on breast tumor genotype characteristics and TIL density, two parameters that are used for predicting patient prognosis and for treatment decision 
Table IV. Hazard ratios and 95\%CIs estimated by univariate Cox regression with respect to DFS and OS in elderly patients (N=257).

\begin{tabular}{|c|c|c|c|c|c|c|}
\hline & Event/Total & Hazard ratio $(95 \% \mathrm{CI})$ & $p$-Value & Event/Total & Hazard ratio $(95 \% \mathrm{CI})$ & $p$-Value \\
\hline & \multicolumn{3}{|c|}{ DFS } & \multicolumn{3}{|c|}{ OS } \\
\hline \multicolumn{7}{|l|}{ PIK3CA } \\
\hline Mutated & $16 / 75$ & $0.81(0.46-1.44)$ & 0.48 & $13 / 75$ & $0.88(0.47-1.65)$ & 0.69 \\
\hline Wild-type & $47 / 182$ & Reference & -- & $38 / 182$ & Reference & -- \\
\hline \multicolumn{7}{|l|}{ TP53 } \\
\hline Mutated & $15 / 58$ & $1.06(0.59-1.90)$ & 0.84 & $12 / 58$ & $1.05(0.55-2.01)$ & 0.88 \\
\hline Wild-type & $48 / 199$ & Reference & -- & $39 / 199$ & Reference & -- \\
\hline \multicolumn{7}{|l|}{ РIКЗСА/ТP53 } \\
\hline No mutation & $23 / 90$ & $0.70(0.26-1.85)$ & 0.47 & $17 / 90$ & $0.59(0.20-1.78)$ & 0.35 \\
\hline PIK3CA mutation only & $11 / 60$ & $0.50(0.17-1.43)$ & 0.19 & $9 / 60$ & $0.52(0.16-1.69)$ & 0.28 \\
\hline TP53 mutation only & $10 / 43$ & $0.63(0.21-1.83)$ & 0.39 & $8 / 43$ & $0.60(0.18-2.01)$ & 0.41 \\
\hline Both & $5 / 15$ & Reference & -- & $4 / 15$ & Reference & -- \\
\hline None $^{1}$ & $14 / 49$ & $0.86(0.31-2.39)$ & 0.77 & $13 / 49$ & $0.99(0.32-3.05)$ & 0.99 \\
\hline TILs* & & $0.74(0.54-1.01)$ & 0.058 & & $0.75(0.53-1.06)$ & 0.10 \\
\hline Ki67^ & & $1.00(0.99-1.01)$ & 0.93 & & $1.00(0.99-1.01)$ & 0.58 \\
\hline Mutations per tumor^ & & $1.00(0.95-1.04)$ & 0.83 & & $0.99(0.94-1.05)$ & 0.78 \\
\hline Mutated genes per tumor^ & & $1.01(0.93-1.09)$ & 0.83 & & $1.02(0.93-1.11)$ & 0.74 \\
\hline \multicolumn{7}{|l|}{ Mutations per tumor } \\
\hline 1 mutation & $16 / 95$ & $0.47(0.25-0.88)$ & 0.018 & $13 / 95$ & $0.43(0.22-0.86)$ & 0.017 \\
\hline$\geq 2$ mutations & $24 / 72$ & Reference & -- & $21 / 72$ & Reference & -- \\
\hline No mutation & $23 / 90$ & $0.71(0.40-1.28)$ & 0.26 & $17 / 90$ & $0.55(0.29-1.06)$ & 0.074 \\
\hline \multicolumn{7}{|l|}{ Mutated genes per tumor } \\
\hline 1 mutated & $16 / 99$ & $0.42(0.22-0.80)$ & 0.008 & $13 / 99$ & $0.39(0.20-0.79)$ & 0.008 \\
\hline$\geq 2$ mutated & $24 / 68$ & Reference & -- & $21 / 68$ & Reference & -- \\
\hline None mutated & $23 / 90$ & $0.67(0.38-1.20)$ & 0.18 & $17 / 90$ & $0.52(0.27-1.00)$ & 0.051 \\
\hline
\end{tabular}

${ }^{1}$ None of the PIK3CA and TP53 were mutated; ^ continuous variable; $* 10 \%$ increments. Bold values show significance.

making. This is the first study addressing differences in tumor genotypes and immune response characteristics in extreme age groups in breast cancer, in an effort to approach the recently highlighted paucity on genomic data that may shed further insights into the biology of breast cancer in young compared to older patients (22).

We observed the expected (23) prevalence of top mutated genes in breast cancer, i.e., TP53 and PIK3CA each $>25 \%$ followed by $<10 \%$ of each GATA3, CDH1, MAP3K1 and $P T E N$. Mutations in the latter two genes characterized tumors of older age, with the exception of one young patient with a $P T E N$ mutated tumor that exhibited two variants described in the context of the PTEN hamartoma tumor syndrome (24). Worth mentioning, the herein identified GATA3 mutations with driver characteristics (abrogative for the corresponding protein, pathogenic in breast cancer according to COSMIC, high allelic fraction) in tumors from younger patients pertained to the same proline at codon 409, while GATA3 mutations in the older age group did not share these characteristics. GATA3 is recurrently mutated in breast cancer, mostly in Luminal A/B tumors (25). High expression of the GATA3 protein (26) and GATA3 mutations (27) have traditionally been considered as favorable prognosticators in early breast cancer and do not seem to interfere with benefit from endocrine therapy. It is reported though, that the impact of GATA3 mutations on prognosis is diverse (favorable and unfavorable) depending on the affected gene domain (28). Clearly, the number of patients carrying GATA3 mutations did not allow for comparisons against outcome in the two study groups. However, the described unique features of GATA3 and PTEN mutations in tumors from extreme age groups and their anticipated diverse impact on outcome prompt for personalizing the interpretation of such alterations for the individual patient.

As previously described, TP53 mutations are unfavorable prognosticators in non-HER2-positive breast cancer, while PIK3CA mutations are favorable in Luminal A/B tumors (15), particularly if occurring in the absence of TP53 mutations (16). For these genes, however, we observed an inverse distribution of mutation patterns in tumors from the two study groups; more TP53 in the young, more PIK3CA in the older patients. This pattern, in association with the expected aggravated characteristics of TP53 and the more favorable ones of PIK3CA mutated tumors (23) is theoretically compatible with the worse outcome traditionally described for breast cancer in young patients $(1,2,10-13)$. However, the expected associations of TP53 with ERnegative, HER2-positive, high grade, highly proliferating tumors, and of PIK3CA with ER-positive tumors (23), were 
Table V. Hazard ratios and 95\% CIs estimated by univariate Cox regression with respect to DFS and OS in young patients (N=88).

\begin{tabular}{|c|c|c|c|c|c|c|}
\hline & Event/Total & Hazard ratio $(95 \% \mathrm{CI})$ & $p$-Value & Event/Total & Hazard ratio $(95 \% \mathrm{CI})$ & $p$-Value \\
\hline & \multicolumn{3}{|c|}{ DFS } & \multicolumn{3}{|c|}{ OS } \\
\hline \multicolumn{7}{|l|}{ PIK $3 C A$} \\
\hline Mutated & $4 / 18$ & $0.71(0.24-2.06)$ & 0.53 & $3 / 18$ & $0.81(0.23-2.79)$ & 0.73 \\
\hline Wild-type & $21 / 70$ & Reference & -- & $15 / 70$ & Reference & -- \\
\hline \multicolumn{7}{|l|}{ TP53 } \\
\hline Mutated & $9 / 29$ & $1.11(0.49-2.52)$ & 0.80 & $7 / 29$ & $1.26(0.49-3.25)$ & 0.64 \\
\hline Wild-type & $16 / 59$ & Reference & -- & $11 / 59$ & Reference & -- \\
\hline PIK3CA/TP53 & & & 0.21 & & 0.41 & \\
\hline Wild-type & $13 / 34$ & $0.56(0.18-1.72)$ & 0.31 & $9 / 34$ & $0.50(0.14-1.86)$ & 0.30 \\
\hline PIK3CA mut only & $0 / 11$ & $0.05(0.00-1.15)$ & 0.061 & $0 / 11$ & $0.08(0.00-1.84)$ & 0.11 \\
\hline TP53 mut only & $5 / 22$ & $0.32(0.09-1.17)$ & 0.085 & $4 / 22$ & $0.34(0.08-1.51)$ & 0.16 \\
\hline Both & $4 / 7$ & Reference & -- & $3 / 7$ & Reference & -- \\
\hline None & $3 / 14$ & $0.35(0.08-1.53)$ & 0.17 & $2 / 14$ & $0.32(0.06-1.80)$ & 0.19 \\
\hline \multicolumn{7}{|l|}{ GATA3 } \\
\hline Mutated & $0 / 9$ & $0.15(0.01-2.67)$ & 0.20 & $0 / 9$ & $0.25(0.01-4.43)$ & 0.34 \\
\hline Wild-type & $25 / 79$ & Reference & -- & $18 / 79$ & Reference & -- \\
\hline TILs* & & $0.87(0.67-1.12)$ & 0.27 & & $0.91(0.69-1.21)$ & 0.53 \\
\hline $\mathrm{Ki} 67^{\wedge}$ & & $1.00(0.99-1.01)$ & 0.91 & & $1.01(0.99-1.02)$ & 0.57 \\
\hline Mutations per tumor ${ }^{\wedge}$ & & $0.96(0.80-1.16)$ & 0.67 & & $0.80(0.54-1.19)$ & 0.28 \\
\hline Mutated genes per tumor^ & & $0.92(0.71-1.19)$ & 0.50 & & $0.78(0.50-1.21)$ & 0.27 \\
\hline \multicolumn{7}{|l|}{ Mutations per tumor^ } \\
\hline 1 mutation & $6 / 33$ & $0.62(0.20-1.92)$ & 0.41 & $5 / 33$ & $0.79(0.21-2.93)$ & 0.72 \\
\hline$\geq 2$ mutations & $6 / 21$ & Reference & -- & $4 / 21$ & Reference & - \\
\hline No mutation & $13 / 34$ & $1.42(0.54-3.73)$ & 0.48 & $9 / 34$ & $1.43(0.44-4.65)$ & 0.55 \\
\hline \multicolumn{7}{|l|}{ Mutated genes per tumor^} \\
\hline 1 mutation & $7 / 36$ & $0.71(0.23-2.24)$ & 0.56 & $6 / 36$ & $0.99(0.25-3.98)$ & 0.99 \\
\hline$\geq 2$ mutations & $5 / 18$ & Reference & -- & $3 / 18$ & Reference & - \\
\hline No mutation & $13 / 34$ & $1.50(0.53-4.20)$ & 0.44 & $9 / 34$ & $1.64(0.44-6.06)$ & 0.46 \\
\hline
\end{tabular}

${ }^{\wedge}$ Continuous variable; $* 10 \%$ increments.

observed in elderly but not in young patients. In the latter group, PIK3CA mutations were seldom detected in the absence of TP53 mutations. These profiles may be partly attributed to the subtype distribution in the young group, which was shifted towards Luminal B and Luminal HER2 tumors, in contrast to the elderly group, where Luminal A tumors prevailed. The subtype profile in the young is in line with previous observations in this age group (9). Breast cancers arising in carriers of pathogenic BRCAl variants would be more likely to bear TP53 mutations and PIK3CA amplification (29) but not the hotspot missense single nucleotide variants (SNVs) observed here. Unfortunately, information on germline status was not available for our patients. It is expected though that part of the examined tumors developed on an inherited background in our young patients, which would further justify the observed TP53 prevalence and distinct PIK3CA mutation profiles. Importantly, other than expected, we did not observe any age-associated difference in prognosis in the examined cohort. Tumors in the two groups were balanced for nodal status and tumor size; hence, these parameters that were previously associated with worse outcome in the young (1, 9), could not have accounted for this controversial finding. Given all the above, our data are in line with more recent observations attributing the worse prognosis of breast cancer in young patients to the intrinsic biology of the tumors, and especially to the Luminal A subtype, while prognosis for all other subtypes is comparable to that observed in elderly patients (30). Overall, our data highlight the difference of TP53 and PIK3CA associated genotypes in young and older patients. This suggests that in young patients (a) mutations in these genes should be examined along with germline data, and (b) the mere presence of PIK3CA mutations may not be helpful in assessing patient prognosis and management.

An additional novel piece of data presented here pertains to anti-tumor host immune response in the extreme age groups of patients with breast cancer. TIL density was more intense in tumors from young compared to elderly patients, which may be attributed to the generally accepted decline in the immune system efficiency with progressing age. A further reason for tumors in the young being more TIL-rich could be the underlying germline BRCAl background in some of the 
Table VI. Hazard ratios and 95\%CIs estimated by multivariate Cox regression with respect to DFS and OS in the entire cohort of patients; results of backwards selection models.

\begin{tabular}{|c|c|c|c|}
\hline & Event/Total & Hazard ratio $(95 \% \mathrm{CI})$ & $p$-Value \\
\hline & \multicolumn{3}{|c|}{ DFS* } \\
\hline \multicolumn{4}{|l|}{ Positive nodes } \\
\hline $0-3$ & $35 / 200$ & Reference & -- \\
\hline$\geq 4$ & $53 / 145$ & $2.17(1.41-3.33)$ & $<0.001$ \\
\hline \multicolumn{4}{|l|}{$\begin{array}{l}\text { Mutated genes } \\
\text { per tumor }\end{array}$} \\
\hline 1 mutated & $23 / 135$ & $0.51(0.29-0.88)$ & 0.016 \\
\hline$\geq 2$ mutated & $29 / 86$ & Reference & -- \\
\hline None mutated & $36 / 124$ & $0.82(0.50-1.34)$ & 0.43 \\
\hline $\begin{array}{l}\text { TILs }^{\wedge} \\
\text { OS** }\end{array}$ & & $0.83(0.69-1.02)$ & 0.071 \\
\hline \multicolumn{4}{|l|}{ Positive nodes } \\
\hline $0-3$ & $21 / 200$ & Reference & \\
\hline$\geq 4$ & $48 / 145$ & $3.15(1.88-5.28)$ & $<0.001$ \\
\hline \multicolumn{4}{|l|}{$\begin{array}{l}\text { Mutated genes } \\
\text { per tumor }\end{array}$} \\
\hline 1 mutated & $19 / 135$ & $0.47(0.26-0.86)$ & 0.015 \\
\hline$\geq 2$ mutated & $24 / 86$ & Reference & \\
\hline None mutated & $26 / 124$ & $0.62(0.35-1.08)$ & 0.093 \\
\hline
\end{tabular}

$\wedge 10 \%$ increments. *PIK3CA/TP53 was removed from the model with $p=0.23$; age (young $v s$. elderly) was removed from the model with $p=0.19$. **PIK3CA/TP53 was removed from the model with $p=0.14$; age (young $v s$. elderly) was removed from the model with $p=0.75$. Bold values show significance.

patients (31), which, although suspected, cannot be proven in our case. The diverse association of TP53 mutations with TIL density, which was prominent in the elderly but not in the young patients, may be related to different mutagenic processes operating in the two age groups (32). The result might be the same mutations, as we observe them with a targeted panel; however, these will operate in a different genomic and hence molecular environment, and may elicit different anti-tumor immune response. These data are new and intriguing for further research and elucidation, particularly with respect to immunotherapy research trials and applications in breast cancer.

Lastly, we observed an adverse prognostic impact of multiple mutated genes on patient outcome, irrespectively of patient age. Because we did not assess pathogenic/ deleterious mutations in particular, because the vast majority of the examined mutations are anticipated to be acquired (somatic), and although the size of the applied panel is evidently too small for counting mutations per megabase, this finding may be related to tumor mutational load or burden (TMB). This parameter has only recently been investigated in breast cancer (33-35) with respect to response to immunotherapy, in the metastatic setting only (35). This gene- and mutation-agnostic parameter has been associated with underlying alterations in particular nucleic acid repair genes (34). Based on the aforementioned reports, a higher number of mutations and mutated genes would be expected to associate with a higher TIL density and better survival. We observed such features with the same panel in a previous report by our Group in de novo but not in relapsed metastatic breast cancer (36). The impact of TMB on the outcome of patients with early breast cancer treated with adjuvant chemotherapy, as is the case for the present cohort, may not necessarily be the same as in various metastatic settings and needs to be elucidated.

Limitations of the present study include (a) the small size of the young age group, which precluded statistical analysis for most individual genes, a concern that has been highlighted already in the first presentation on breast cancer by The Cancer Genome Atlas (TCGA) (23); (b) the fact that information on patient germline status was not available. For the above reasons, our study should be considered as hypothesis generating and all findings should be pursued in larger studies.

In conclusion, here, we presented differences in the mutational patterns of tumors in young compared to elderly patients, pertaining to genes frequently mutated in breast cancer, such as TP53, PIK3CA, GATA3 and PTEN. We also identified differences in the two age groups with respect to anti-tumor immune response in general and to TP53 mutations in particular. If further validated, these findings, along with the novel finding on the adverse prognostic effect of gene-agnostic multiple mutations will aid in understanding molecular markers and underlying mechanisms for testing existing and new drugs in the context of personalized treatment of early breast cancer.

\section{Funding Information}

This study was supported by an internal Hellenic Cooperative Oncology Group (HeCOG) translational research grant (HE TRANS_BR). The funders played no role in study design, data collection and analysis, decision to publish, or preparation of the manuscript. This study was also partly supported by the Greek General Secretary for Research and Technology (GSRT) Program, Research in Excellence II, funded by $75 \%$ from the European Union and the Operational Program "Education \& Lifelong Learning" ESPA-THALIS\#266 of the Ministry of Education, Lifelong Learning \& Religious Affairs.

\section{Conflicts of Interest}

The Authors declare no conflicts of interest in regard to this study.

\section{Authors' Contributions}

Conceptualization: AN, VK, GF; Formal Analysis: GAK, EG; Investigation: KP, MB, KC; Resources: AN, FZ, GP, HG, GO, DP, ES, NA, IN, PP, IB, GA, IA, GF; Writing - editing: AN, VK, GAK, $\mathrm{KP}$, GF; Writing - review and editing: All Authors. 


\section{Acknowledgements}

The Authors are indebted to all patients and their families for their trust and participation in the HeCOG trials and for the provision of biological material for research purposes. The Authors wish to thank Ms Emily Daskalaki for excellent technical assistance with NGS and for NGS library construction; Ms Sofia Chrisafi, MSc for performing IHC; and Ms Helen Sgouramalli, MSc for block sectioning. Part of this work was presented at St. Gallen International Breast Cancer Conference 2019.

\section{References}

1 Gnerlich JL, Deshpande AD, Jeffe DB, Sweet A, White N and Margenthaler JA: Elevated breast cancer mortality in women younger than age 40 years compared with older women is attributed to poorer survival in early-stage disease. J Am Coll Surg 208(3): 341-347, 2009. PMID: 19317994. DOI: 10.1016/j.jamcollsurg.2008.12.001

2 Stickeler E: Prognostic and predictive markers for treatment decisions in early breast cancer. Breast Care (Basel) 6(3): 193198, 2011. DOI: 10.1159/000329471

3 Colleoni M, Rotmensz N, Robertson C, Orlando L, Viale G, Renne G, Luini A, Veronesi P, Intra M, Orecchia R, Catalano G, Galimberti V, Nole F, Martinelli G and Goldhirsch A: Very young women ( $<35$ years) with operable breast cancer: Features of disease at presentation. Ann Oncol 13(2): 273-279, 2002. PMID: 11886005. DOI: 10.1093/annonc/mdf039

4 Euler U, Knopf B and Tulusan AH: Breast cancer in young women aged 35 or less. J Clin Oncol 22(14): 754-754, 2004.

5 Poppe A, Brouckaert O, Laenen A, Soubry A, Remmerie C, Floris G, Leunen K, Berteloot P, Amant F, Vergote I, Nevelsteen I, Smeets A, Christiaens M-R, Weltens C, Peeters S, Van Limbergen E, Wildiers H and Neven P: Abstract p6-09-11: Independent prognostic value of age depends on breast cancer subtype. Cancer Res 76: P6-09-11-P06-09-11, 2016. DOI: 10.1158/1538-7445.Sabcs15-p6-09-11

6 Bonnier P, Romain S, Charpin C, Lejeune C, Tubiana N, Martin PM and Piana L: Age as a prognostic factor in breast cancer: Relationship to pathologic and biologic features. Int J Cancer 62(2): 138-144, 1995. PMID: 7622286. DOI: 10.1002/ijc.2910620205

7 Sweeney C, Blair CK, Anderson KE, Lazovich D and Folsom AR: Risk factors for breast cancer in elderly women. Am J Epidemiol 160(9): 868-875, 2004. PMID: 15496539. DOI: 10.1093/aje/kwh276

8 Gomez-Flores-Ramos L, Castro-Sanchez A, Pena-Curiel O and Mohar-Betancourt A: Molecular biology in young women with breast cancer: From tumor gene expression to DNA mutations. Rev Invest Clin 69(4): 181-192, 2017. PMID: 28776603. DOI: 10.24875/ric. 17002225

9 Azim HA Jr. and Partridge AH: Biology of breast cancer in young women. Breast Cancer Res 16(4): 427, 2014. PMID: 4303229. DOI: $10.1186 / \mathrm{s} 13058-014-0427-5$

10 Aebi S, Gelber S, Castiglione-Gertsch M, Gelber RD, Collins J, Thurlimann B, Rudenstam CM, Lindtner J, Crivellari D, CortesFunes H, Simoncini E, Werner ID, Coates AS and Goldhirsch A: Is chemotherapy alone adequate for young women with oestrogen-receptor-positive breast cancer? Lancet 355(9218): 1869-1874, 2000. PMID: 10866443. DOI: 10.1016/s01406736(00)02292-3
11 Arriagada R, Le MG, Dunant A, Tubiana M and Contesso G: Twenty-five years of follow-up in patients with operable breast carcinoma: Correlation between clinicopathologic factors and the risk of death in each 5-year period. Cancer 106(4): 743-750, 2006. PMID: 16411216. DOI: $10.1002 /$ cncr.21659

12 Goldhirsch A, Gelber RD, Yothers G, Gray RJ, Green S, Bryant J, Gelber S, Castiglione-Gertsch M and Coates AS: Adjuvant therapy for very young women with breast cancer: Need for tailored treatments. J Natl Cancer Inst Monogr 30: 44-51, 2001. PMID: 11773291. DOI: 10.1093/oxfordjournals .jncimonographs.a003459

13 Kroman N, Jensen MB, Wohlfahrt J, Mouridsen HT, Andersen PK and Melbye M: Factors influencing the effect of age on prognosis in breast cancer: Population based study. BMJ 320(7233): 474-478, 2000. PMID: 10678859. DOI: 10.1136/bmj.320.7233.474

14 Encinas G, Sabelnykova VY, de Lyra EC, Hirata Katayama ML, Maistro S, de Vasconcellos Valle PWM, de Lima Pereira GF, Rodrigues LM, de Menezes Pacheco Serio PA, de Gouvea A, Geyer FC, Basso RA, Pasini FS, Del Pilar Esteves Diz M, Brentani MM, Guedes Sampaio Goes JC, Chammas R, Boutros PC and Koike Folgueira MAA: Somatic mutations in early onset luminal breast cancer. Oncotarget 9(32): 22460-22479, 2018. PMID: 29854292. DOI: 10.18632/oncotarget.25123

15 Fountzilas G, Giannoulatou E, Alexopoulou Z, Zagouri F, Timotheadou E, Papadopoulou K, Lakis S, Bobos M, Poulios C, Sotiropoulou M, Lyberopoulou A, Gogas H, Pentheroudakis G, Pectasides D, Koutras A, Christodoulou C, Papandreou C, Samantas E, Papakostas P, Kosmidis P, Bafaloukos D, Karanikiotis C, Dimopoulos MA and Kotoula V: Tp53 mutations and protein immunopositivity may predict for poor outcome but also for trastuzumab benefit in patients with early breast cancer treated in the adjuvant setting. Oncotarget 7(22): 32731-32753, 2016. PMID: 27129168. DOI: 10.18632/oncotarget.9022

16 Kotoula V, Karavasilis V, Zagouri F, Kouvatseas G, Giannoulatou E, Gogas H, Lakis S, Pentheroudakis G, Bobos M, Papadopoulou K, Tsolaki E, Pectasides D, Lazaridis G, Koutras A, Aravantinos G, Christodoulou C, Papakostas P, Markopoulos C, Zografos G, Papandreou C and Fountzilas G: Effects of tp53 and pik3ca mutations in early breast cancer: A matter of co-mutation and tumor-infiltrating lymphocytes. Breast Cancer Res Treat 158(2): 307-321, 2016. PMID. DOI: 10.1007/s10549-016-3883-z.

17 Papaxoinis G, Kotoula V, Alexopoulou Z, Kalogeras KT, Zagouri F, Timotheadou E, Gogas H, Pentheroudakis G, Christodoulou C, Koutras A, Bafaloukos D, Aravantinos G, Papakostas P, Charalambous E, Papadopoulou K, Varthalitis I, Efstratiou I, Zaramboukas T, Patsea H, Scopa CD, Skondra M, Kosmidis P, Pectasides D and Fountzilas G: Significance of pik3ca mutations in patients with early breast cancer treated with adjuvant chemotherapy: A hellenic cooperative oncology group (hecog) study. PLoS One 10(10): e0140293, 2015. PMID: 26452060. DOI: 10.1371/journal.pone.0140293

18 Kotoula V, Chatzopoulos K, Lakis S, Alexopoulou Z, Timotheadou E, Zagouri F, Pentheroudakis G, Gogas H, Galani E, Efstratiou I, Zaramboukas T, Koutras A, Aravantinos G, Samantas E, Psyrri A, Kourea H, Bobos M, Papakostas P, Kosmidis P, Pectasides D and Fountzilas G: Tumors with highdensity tumor infiltrating lymphocytes constitute a favorable entity in breast cancer: A pooled analysis of four prospective adjuvant trials. Oncotarget 7(4): 5074-5087, 2016. PMID: 26506242. DOI: $10.18632 /$ oncotarget.6231 
19 Kotoula V, Lyberopoulou A, Papadopoulou K, Charalambous E, Alexopoulou Z, Gakou C, Lakis S, Tsolaki E, Lilakos K and Fountzilas G: Evaluation of two highly-multiplexed custom panels for massively parallel semiconductor sequencing on paraffin DNA. PLoS One 10(6): e0128818, 2015. PMID: 26039550. DOI: 10.1371/journal.pone.0128818

20 Sun H and Yu G: New insights into the pathogenicity of nonsynonymous variants through multi-level analysis. Sci Rep 9(1): 1667, 2019. PMID: 30733553. DOI: 10.1038/s41598-01838189-9

21 Martincorena I, Raine KM, Gerstung M, Dawson KJ, Haase K, Van Loo P, Davies H, Stratton MR and Campbell PJ: Universal patterns of selection in cancer and somatic tissues. Cell 171(5): 1029-1041 e1021, 2017. PMID: 29056346. DOI: 10.1016/j.cell.2017.09.042

22 Poggio F, Lambertini M, Bighin C, Conte B, Blondeaux E, D'Alonzo A, Dellepiane C, Boccardo F and Del Mastro L: Management of young women with early breast cancer. ESMO Open 3: e000458, 2018. PMID: 6267460. DOI: 10.1136/esmoopen2018-000458

23 Cancer Genome Atlas N: Comprehensive molecular portraits of human breast tumours. Nature 490(7418): 61-70, 2012. PMID: 23000897. DOI: $10.1038 /$ nature 11412 .

24 Hobert JA and Eng C: PTEN hamartoma tumor syndrome: An overview. Genet Med 11: 687-694, 2009. PMID: 19668082. DOI: $10.1097 /$ GIM.0b013e3181ac9aea

25 Usary J, Llaca V, Karaca G, Presswala S, Karaca M, He X, Langerod A, Karesen R, Oh DS, Dressler LG, Lonning PE, Strausberg RL, Chanock S, Borresen-Dale AL and Perou CM: Mutation of gata3 in human breast tumors. Oncogene 23(46): 7669-7678, 2004. PMID: 15361840. DOI: 10.1038/sj.onc.1207966

26 Fararjeh AS, Tu SH, Chen LC, Liu YR, Lin YK, Chang HL, Chang HW, Wu CH, Hwang-Verslues WW and Ho YS: The impact of the effectiveness of gata3 as a prognostic factor in breast cancer. Hum Pathol 80: 219-230, 2018. PMID: 29902578. DOI: 10.1016/j.humpath.2018.06.004.

27 Jiang YZ, Yu KD, Zuo WJ, Peng WT and Shao ZM: Gata3 mutations define a unique subtype of luminal-like breast cancer with improved survival. Cancer 120(9): 1329-1337, 2014. PMID: 24477928. DOI: $10.1002 / \mathrm{cncr} .28566$

28 Takaku M, Grimm SA, Roberts JD, Chrysovergis K, Bennett BD, Myers P, Perera L, Tucker CJ, Perou CM and Wade PA: Gata3 zinc finger 2 mutations reprogram the breast cancer transcriptional network. Nat Commun 9(1): 1059, 2018. PMID: 5849768. DOI: 10.1038/s41467-018-03478-4

29 Annunziato S, de Ruiter JR, Henneman L, Brambillasca CS, Lutz C, Vaillant F, Ferrante F, Drenth AP, van der Burg E, Siteur B, van Gerwen B, de Bruijn R, van Miltenburg MH, Huijbers IJ, van de Ven M, Visvader JE, Lindeman GJ, Wessels LFA and Jonkers J: Comparative oncogenomics identifies combinations of driver genes and drug targets in brca1-mutated breast cancer. Nat Commun 10(1): 397, 2019. PMID: 30674894. DOI: 10.1038/s41467-019-08301-2

30 Sheridan W, Scott T, Caroline S, Yvonne Z, Vanessa B, David V, Karen G and Stephen C: Breast cancer in young women: Have the prognostic implications of breast cancer subtypes changed over time? Breast Cancer Res Treat 147(3): 617-629, 2014. PMID: 25209005. DOI: 10.1007/s10549-014-3125-1

31 Sonderstrup IMH, Jensen MB, Ejlertsen B, Eriksen JO, Gerdes AM, Kruse TA, Larsen MJ, Thomassen $M$ and Laenkholm AV: Evaluation of tumor-infiltrating lymphocytes and association with prognosis in brca-mutated breast cancer. Acta Oncol 58(3): 363-370, 2019. PMID: 30614364. DOI: 10.1080/0284186X.2018.1539239

32 Alexandrov LB, Nik-Zainal S, Wedge DC, Aparicio SA, Behjati S, Biankin AV, Bignell GR, Bolli N, Borg A, Borresen-Dale AL, Boyault S, Burkhardt B, Butler AP, Caldas C, Davies HR, Desmedt C, Eils R, Eyfjord JE, Foekens JA, Greaves M, Hosoda F, Hutter B, Ilicic T, Imbeaud S, Imielinski M, Jager N, Jones DT, Jones D, Knappskog S, Kool M, Lakhani SR, Lopez-Otin C, Martin S, Munshi NC, Nakamura H, Northcott PA, Pajic M, Papaemmanuil E, Paradiso A, Pearson JV, Puente XS, Raine K, Ramakrishna M, Richardson AL, Richter J, Rosenstiel P, Schlesner M, Schumacher TN, Span PN, Teague JW, Totoki Y, Tutt AN, Valdes-Mas R, van Buuren MM, van't Veer L, VincentSalomon A, Waddell N, Yates LR, Australian Pancreatic Cancer Genome I, Consortium IBC, Consortium IM-S, PedBrain I, Zucman-Rossi J, Futreal PA, McDermott U, Lichter P, Meyerson M, Grimmond SM, Siebert R, Campo E, Shibata T, Pfister SM, Campbell PJ and Stratton MR: Signatures of mutational processes in human cancer. Nature 500(7463): 415-421, 2013. PMID: 3776390. DOI: 10.1038/nature 12477

33 Barroso-Sousa R, Jain E, Kim D, Partridge AH, Cohen O and Wagle N: Determinants of high tumor mutational burden (tmb) and mutational signatures in breast cancer. J Clin Oncol 36: 1010-1010, 2018. DOI: 10.1200/JCO.2018.36.15_suppl.1010

34 Thomas A, Routh ED, Pullikuth A, Jin G, Su J, Chou JW, Hoadley KA, Print C, Knowlton N, Black MA, Demaria S, Wang E, Bedognetti D, Jones WD, Mehta GA, Gatza ML, Perou CM, Page DB, Triozzi P and Miller LD: Tumor mutational burden is a determinant of immune-mediated survival in breast cancer. Oncoimmunology 7(10): e1490854, 2018. PMID: 6207420. DOI: 10.1080/2162402X.2018.1490854.

35 Samstein RM, Lee C-H, Shoushtari AN, Hellmann MD, Shen R, Janjigian YY, Barron DA, Zehir A, Jordan EJ, Omuro A, Kaley TJ, Kendall SM, Motzer RJ, Hakimi AA, Voss MH, Russo P, Rosenberg J, Iyer G, Bochner BH, Bajorin DF, Al-Ahmadie HA, Chaft JE, Rudin CM, Riely GJ, Baxi S, Ho AL, Wong RJ, Pfister DG, Wolchok JD, Barker CA, Gutin PH, Brennan CW, Tabar V, Mellinghoff IK, DeAngelis LM, Ariyan CE, Lee N, Tap WD, Gounder MM, D’Angelo SP, Saltz L, Stadler ZK, Scher HI, Baselga J, Razavi P, Klebanoff CA, Yaeger R, Segal NH, Ku GY, DeMatteo RP, Ladanyi M, Rizvi NA, Berger MF, Riaz N, Solit DB, Chan TA and Morris LGT: Tumor mutational load predicts survival after immunotherapy across multiple cancer types. Nat Genet 51(2): 202-206, 2019. PMID: 30643254. DOI: 10.1038/s41588-018-0312-8

36 Kotoula V, Tsakiri K, Koliou GA, Lazaridis G, Papadopoulou K, Giannoulatou E, Tikas I, Christodoulou C, Chatzopoulos K, Bobos M, Pentheroudakis G, Tsolaki E, Batistatou A, Kotsakis A, Koutras A, Linardou H, Razis E, Res E, Pectasides D and Fountzilas G: Relapsed and de novo metastatic her2-positive breast cancer treated with trastuzumab: Tumor genotypes and clinical measures associated with patient outcome. Clin Breast Cancer 19(2): 113-125 e114, 2019. PMID: 30545790. DOI: 10.1016/j.clbc.2018.10.014
Received December 3, 2019

Revised December 16, 2019

Accepted December 17, 2019 